\title{
Steroid-sensitive gene-1 is an androgen-regulated gene expressed in prostatic smooth muscle cells in vivo
}

\author{
D Marcantonio ${ }^{1}$, L E Chalifour ${ }^{1}$, M A Alaoui-Jamali ${ }^{1,2}$ and \\ H T Huynh ${ }^{1,2}$
}

${ }^{1}$ Department of Medicine, Lady Davis Institute for Medical Research, Sir Mortimer B Davis Jewish General Hospital, McGill University, 3755, Chemin Côte Ste Catherine, Montréal, Québec, Canada H3T 1E2

${ }^{2}$ Department of Oncology, Lady Davis Institute for Medical Research, Sir Mortimer B Davis Jewish General Hospital, McGill University, 3755, Chemin Côte Ste Catherine, Montréal, Québec, Canada H3T 1E2

(Requests for offprints should be addressed to H T Huynh who is now at Molecular Endocrinology Laboratory, National Cancer Centre, 11 Hospital Drive, Singapore 169610;

Email: cmrhth@nccs.com.sg or LE Chalifour; Email: czlc@musica.mcgill.ca)

\begin{abstract}
Steroid-sensitive gene-1 (SSG1) is a novel gene we cloned, found regulated by $17 \beta$-estradiol in the rat uterus and mammary gland, and over-expressed in 7,12-dimethylbenz $(a)$ anthracene-induced rat mammary tumors. We show here that SSG1 mRNA and protein expression are regulated by androgens in the rat ventral prostate. Increases in SSG1 mRNA levels were detected by Northern blotting after $24 \mathrm{~h}$ and reached a 27 -fold peak $96 \mathrm{~h}$ following castration, relative to SSG1 mRNA expression in sham-operated rats. Dihydrotestosterone or testosterone supplementation of castrated rats prevented this rise in SSG1 mRNA. In contrast with SSG1 mRNA expression, SSG1 protein was
\end{abstract}

decreased 16-fold 2 weeks following castration but was at control levels in the prostates of castrated rats receiving dihydrotestosterone or testosterone. Although SSG1 is regulated by androgens in vivo, treatment of LnCap cells with dihydrotestosterone, cyproterone acetate or flutamide did not result in the regulation of SSG1 protein levels in vitro. Immunofluorescence studies show that SSG1 is mainly expressed in prostatic smooth muscle cells. These results indicate that SSG1 is an androgenregulated gene that is expressed in the smooth muscle component of the rat ventral prostate in vivo.

Fournal of Molecular Endocrinology (2001) 26, 175-184

\section{INTRODUCTION}

Steroid-sensitive gene-1 (SSG1) is a novel gene recently cloned from a rat uterus cDNA library. The SSG1 cDNA of $3.719 \mathrm{~kb}$ encodes a putative nuclear protein of $41.8 \mathrm{kDa}$. SSG1 shares no significant homology with existing sequences yet is highly homologous to mouse, rat and human expressed sequence tags (Marcantonio et al. 2001). We previously showed that SSG1 is regulated by $17 \beta-$ estradiol $\left(\mathrm{E}_{2}\right)$ in the rat uterus and mammary gland in a tissue-specific manner. In the normal rat mammary gland, long term treatment with $\mathrm{E}_{2}$ induced high levels of SSG1 protein expression in mammary tissue and SSG1 protein levels were consistently overexpressed in the hormone-dependent 7,12-dimethylbenz( $a$ )anthracene-induced (DMBA) rat mammary tumors (Marcantonio et al. 2001).

Although SSG1 was initially isolated by its responsiveness to $E_{2}$ in the rat uterus and mammary gland, regulation of SSG1 may not be limited to $\mathrm{E}_{2}$. The prostate is an androgen-dependent organ and circulating androgens are required for prostate development and maintenance (Cunha et al. 1987). Furthermore, androgens are implicated in both benign prostate hyperplasia and prostate cancer (Wilding 1995). Eighty to eighty-five percent of the normal rat ventral prostate is composed of androgen-sensitive epithelial cells (Colombel \& Buttyan 1995). The minority of non-epithelial cells consist of endothelial cells which form the prostatic vasculature, smooth muscle cells which surround 
the glands and some afferent blood vessels, nerves, and fibroblasts (Shabisgh et al. 1999). Androgen receptor (AR)-negative fibroblasts and AR-positive smooth muscle cells are the predominant cell types forming the prostatic stroma (Flickinger 1972). The main stromal interaction of adult prostatic epithelium is with the surrounding smooth muscle (Hayward et al. 1997).

Surgical castration results in a rapid decline in serum testosterone levels followed by a gradual depletion of dihydrotestosterone (DHT) in prostatic tissue. Within $6 \mathrm{~h}$ following castration, serum testosterone levels are decreased by approximately $98 \%$, DHT is reduced by $35 \%$ and after $12 \mathrm{~h}$, DHT in the prostate is reduced to $5 \%$ of intact levels (Kyprianou \& Isaacs 1988). In the rat, androgen deprivation triggers apoptosis in the androgendependent epithelial cells within a day after castration and results in glandular involution with greater than $85 \%$ of cellular losses occurring within two weeks (Colombel \& Buttyan 1995). Apoptosis is a rare event in prostatic smooth muscle cells following castration (Shabisgh et al. 1999). However, castration results in the disintegration and disappearance of smooth muscle bundles and is associated with the loss of prostatic smooth muscle differentiation markers (Hayward et al. 1996, 1997).

The prostate and mammary gland share many similarities. Both mammary and prostatic tissue require steroid hormones, estrogens and androgens, for differentiation, growth and function respectively, and both glands undergo involution following hormonal withdrawal (Lopez-Otin \& Diamandis 1998). Furthermore, the initial stages of breast/ prostate cancer are hormone dependent and are sensitive to anti-estrogen/anti-androgen treatments respectively (Lopez-Otin \& Diamandis 1998). In the mammary gland, SSG1 is regulated by $\mathrm{E}_{2}$. In this study, we set out to determine whether the SSG1 gene is regulated by androgens in the prostate.

\section{MATERIALS AND METHODS}

\section{Experimental animals}

All animal studies were performed in accordance with the regulations of the Canadian Council of Animal Care and the Animal Care Committee of the Lady Davis Institute for Medical Research. Male Sprague-Dawley rats weighing 300-350 g (Charles River, Québec, Canada) (6 rats/group) were either castrated or 'sham' castrated (scrotal incision only) under ketamine $(15 \mathrm{mg} / \mathrm{kg})$ : xylazine $(10 \mathrm{mg} / \mathrm{kg})$ anaesthesia. Rats were killed after 6, 24, 48, 96 and $120 \mathrm{~h}$. The ventral prostate was immediately removed, snap frozen in liquid nitrogen and stored at $-80{ }^{\circ} \mathrm{C}$ until needed.

In a second study, two weeks after castration, rats (3 animals/group) were implanted in the dorsal area with silastic tubing packed with testosterone to release $1 \cdot 2,2 \cdot 4$ or $3 \cdot 6 \mu \mathrm{g} / \mathrm{kg}$ per day or with DHT to release $1 \cdot 2,2 \cdot 4$ or $3 \cdot 6 \mu \mathrm{g} / \mathrm{kg}$ per day. Control rats (3 animals/group), were sham operated or were castrated and received dorsal implants of empty tubing. Rats were killed 21 days after hormone implantation, ventral prostates were collected and tissue was stored at $-80{ }^{\circ} \mathrm{C}$ until needed.

Finasteride, $5 \mathrm{mg}$ tablets (Merck Frosst, Montreal, Quebec, Canada), was dissolved in water. Male Sprague-Dawley rats received $10 \mathrm{mg}$ finasteride/kg body weight by gavage daily for 21 days (3 animals/group) whereas control rats received vehicle by gavage ( 3 animals/group). At the end of the treatment, ventral prostates were collected, snap frozen in liquid nitrogen and stored at $-80{ }^{\circ} \mathrm{C}$ until needed.

\section{RNA isolation and Northern blot analysis}

RNAzol B (Tel-Test Inc., Friendswood, TX, USA) was utilized to extract total RNA from tissue as described by the manufacturer. Total RNA (30-45 $\mu \mathrm{g})$ was denatured, electrophoresed through a $1 \%$ formaldehyde-agarose gel and transferred by downward alkaline capillary blotting onto Zeta Probe GT nylon membranes (BioRad, Montréal, Québec, Canada) using $50 \mathrm{mM} \quad \mathrm{NaOH}$. SSG1 mRNA was visualized by Northern blot hybridization using the entire SSG1 cDNA, radio-labeled with $\left[{ }^{32} \mathrm{P}\right] \alpha$-dCTP by random priming using the $\mathrm{T}^{7}$ Quick Prime Kit (Amersham Pharmacia, Baie D'Urfé, Canada), as directed by the manufacturer. Prehybridization, hybridization and washing were performed as previously described in Huynh (1998). Blots were subjected to autoradiography with intensifying screen at $-80{ }^{\circ} \mathrm{C}$. Blots were stripped and then hybridized with glyceraldehyde-3phosphate dehydrogenase (GAPDH) to normalize for minor loading differences.

\section{Protein extraction and Western blot analysis}

Total protein was extracted from rat prostate tissue as described in Marcantonio et al. (2001). Rabbit polyclonal SSG1 antibody was created using synthetic peptides corresponding to predicted amino acids 3 to 29 (TVRGPSVSEQLYPLPR KEQQREKPQA) of the rat SSG1 gene and characterized as described in Marcantonio et al. (2001). Total protein, $75 \mu \mathrm{g}$, was subject to SDS-PAGE through a $10 \%$ polyacrylamide gel and 
electrotransferred onto nitrocellulose membranes (BioRad) according to standard protocol. The membranes were blocked by incubation in TTBS $(150 \mathrm{mM} \mathrm{NaCl}, 10 \mathrm{mM}$ Tris- $\mathrm{HCl}, \mathrm{pH} 7 \cdot 4$ and $0 \cdot 1 \%$ Tween-20) buffer containing 7\% dried milk for $1 \mathrm{~h}$ and then probed with affinity-purified anti-SSG1 rabbit polyclonal antibody in $1 \%$ milk in TTBS, at a concentration of $1 \mu \mathrm{g} / \mathrm{ml}$ at room temperature for $1 \mathrm{~h}$. After four 15-min washes with TTBS, membranes were incubated with a peroxidaseconjugated secondary goat anti-rabbit antibody (Amersham Pharmacia). Immune complexes were detected using the enhanced chemiluminescence detection reagents (Amersham Pharmacia), as recommended by the manufacturer. Blots were stripped and then immunoblotted with anti- $\alpha$ tubulin antibody as described above to normalize for protein loading.

\section{Immunofluorescence}

Normal prostate tissue was fixed in $10 \%$ buffered formalin for $24 \mathrm{~h}$, dehydrated and embedded in paraffin. Tissue sections, $5 \mu \mathrm{m}$ in thickness, were prepared and mounted on poly-L-lysine coated slides. Tissue sections were deparaffinized and rehydrated by successive incubations in toluene, $100 \%$ ethanol, $95 \%$ ethanol and finally in water. Prostate sections were equilibrated in phosphatebuffered saline (PBS). Deparaffinized tissue sections were blocked for $1.5 \mathrm{~h}$ at room temperature with blocking solution containing $0 \cdot 2 \%$ gelatin, $2 \%$ bovine serum albumin and $2 \%$ normal goat serum in PBS. Samples were incubated with primary antibody, anti-SSG1, at $20 \mu \mathrm{g} / \mu \mathrm{l}, 10 \mu \mathrm{g} / \mu \mathrm{l}$ or $5 \mu \mathrm{g} / \mu \mathrm{l}$ blocking solution overnight at $4{ }^{\circ} \mathrm{C}$ in a humid chamber. For the negative control, tissue sections were incubated in blocking solution overnight at $4{ }^{\circ} \mathrm{C}$ in a humid chamber in the absence of primary antibody. Unbound primary antibody was removed by washing three times for $5 \mathrm{~min}$ each time with PBS containing $0 \cdot 1 \%$ bovine serum albumin. Samples were incubated with secondary antibody, goat anti-rabbit IgG conjugated to Texas Red at a concentration of $1 \mu \mathrm{g} / \mathrm{ml}$. Tissue sections were washed in PBS containing $0 \cdot 1 \%$ bovine serum albumin and then with PBS alone. Samples were mounted and photographs were taken at $\times 400$ magnification using an Olympus $\mathrm{BH} 2$ microscope equipped with epifluorescence.

\section{Cell culture}

LnCap cells were maintained in RPMI media supplemented with $10 \%$ fetal calf serum. Cells were plated in RPMI media containing 5\% fetal calf serum on $100 \mathrm{~mm}$ plates. At a confluence of $60-70 \%$, cells were washed twice in $5 \%$ charcoal stripped serum-phenol red free RPMI and incubated in this media. Twenty-four hours later, LnCap cells were treated with DHT, cyproterone acetate or flutamide for $72 \mathrm{~h}$.

\section{RNA and protein quantitation}

The optical density of the hybridization signals was quantified by densitometric scanning (HPScanJet, Scion Image Quant Release Beta 3 Software; NIH, Bethesda, MD, USA) of the autoradiograms. Levels of mRNA expression were corrected for minor loading differences by normalizing to GAPDH mRNA expression. Levels of protein expression were corrected for by normalizing to $\alpha$-tubulin protein levels. Statistical analyses were performed using Graph Pad Prism and a $P$ value of $<0.05$ was considered significant.

\section{RESULTS}

\section{Castration induces SSG1 mRNA expression in the rat ventral prostate}

The effect of castration-induced androgen ablation on SSG1 mRNA expression was determined in the rat ventral prostate (Fig. 1A). Northern blotting of SSG1 mRNA expression indicates that SSG1 mRNA expression is low in sham-castrated rats (SC) at $6 \mathrm{~h}$ and did not significantly differ at 48,96 and $120 \mathrm{~h}$ post sham castration (data not shown). Following castration, there was a significant 2-fold increase $(P<0 \cdot 05)$ in SSG1 mRNA expression at $24 \mathrm{~h}$. SSG1 mRNA levels peaked at $96 \mathrm{~h}$ post castration and were 27-fold greater than levels of SSG1 mRNA expression in sham-operated rats (Fig. 1B).

\section{SSG1 mRNA and protein levels are regulated in the ventral prostates of castrated rats receiving androgen supplementation}

The involuted ventral prostate of the long-term castrated rat can be regenerated following testosterone or DHT supplementation (Colombel \& Buttyan 1995). In our study rats castrated 2 weeks earlier received either $0,1 \cdot 2,2 \cdot 4$ or $3 \cdot 6 \mu \mathrm{g} / \mathrm{kg}$ per day DHT or testosterone for 21 days. In agreement with the results shown in Fig. 1, SSG1 mRNA expression was low but detectable in the prostate of shamoperated rats (Fig. 2, lane SC). Two weeks following castration, SSG1 mRNA levels in the ventral prostate of castrated rats were significantly increased by 8 -fold $(P<0 \cdot 01)$ when compared with 
A

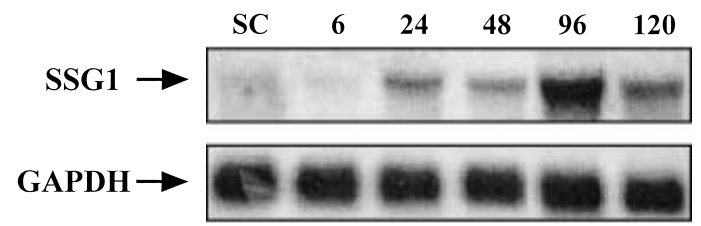

B

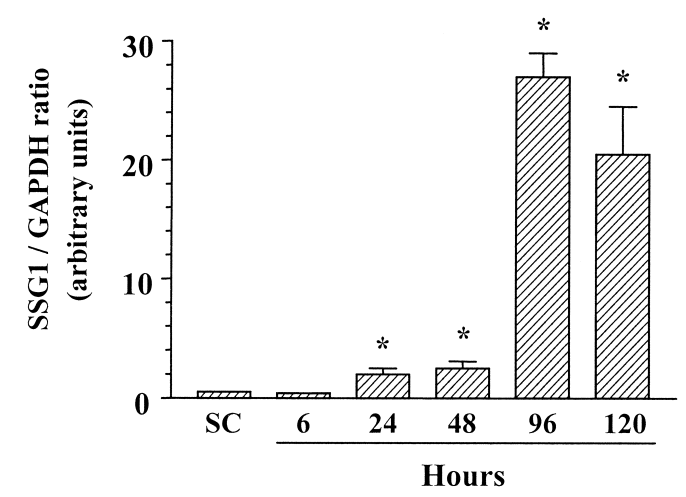

FIGURE 1. Effect of castration on SSG1 gene expression in the ventral prostate. (A) The $3 \cdot 8 \mathrm{~kb}$ SSG1 mRNA was detected by Northern blot analysis in the ventral prostate of sham-castrated rats $(\mathrm{SC}, n=6)$ and in the prostate of rats at $6,24,48,96$ and $120 \mathrm{~h}$ following castration $(n=6)$. SSG1 expression in sham-castrated rats is shown only at $6 \mathrm{~h}$ as SSG1 mRNA expression did not significantly differ at 24, 48, 96 and $120 \mathrm{~h}$ post sham castration. GAPDH mRNA expression is also indicated and representative blots are shown. (B) Expression of SSG1 mRNA was quantitated by densitometric scanning of autoradiograms, normalized to GAPDH mRNA expression and is plotted. Values are expressed in arbitrary units with the means \pm s.E. shown. Statistical significance $(P<0 \cdot 05)$ is indicated by an asterisk.

levels of SSG1 mRNA expression in control prostates (Fig. 2, lanes C). Northern blot analysis indicates that levels of SSG1 mRNA expression in the two-week castrated rats receiving DHT or testosterone were at low levels and were similar to SSG1 mRNA expression in sham-operated prostate tissue. Although DHT and testosterone vary in potency, both androgens were effective in decreasing SSG1 mRNA expression to levels expressed in the sham-operated rat.

In contrast to SSG1 mRNA, SSG1 protein expression in the rat ventral prostate of shamcastrated rats was significantly greater $(P<0 \cdot 01)$ than levels of SSG1 protein expression in the prostates of castrated rats (Fig. 3). Castration resulted in a 16-fold decrease in the levels of

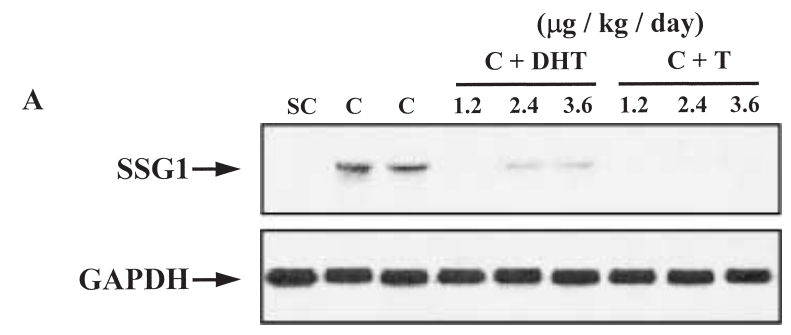

B

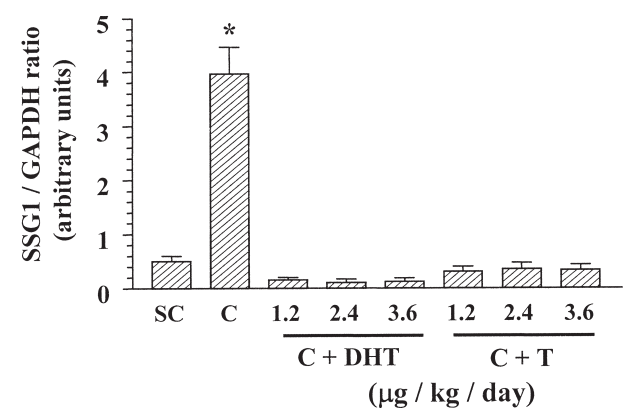

FIGURE 2. Effect of castration and androgen replacement on SSG1 mRNA in the ventral prostate.

(A) Northern blotting was performed on $30 \mu \mathrm{g}$ total RNA extracted from the ventral prostate of shamcastrated (SC, $n=3$ ), 2-week-castrated (C, $n=3$ ) or 2-week-castrated rats treated with $1 \cdot 2,2 \cdot 4$ or $3 \cdot 6 \mu \mathrm{g} / \mathrm{kg}$ per day DHT or $1 \cdot 2,2 \cdot 4$ or $3.6 \mu \mathrm{g} / \mathrm{kg}$ per day testosterone (T) $(n=3)$, for 21 days. Blots were hybridized to radioactive SSG1- and GAPDH-specific cDNA probes. Representative blots are shown. (B) SSG1 and GAPDH mRNA expression was quantitated by densitometric scanning of autoradiograms and SSG1 mRNA expression was normalized to GAPDH mRNA expression. Values are expressed in arbitrary units with the means \pm s.E. shown. Statistical significance, when compared with SSG1 expression in sham-castrated samples $(P<0 \cdot 01)$, is indicated by an asterisk.

SSG1 protein expression in the ventral prostate. In the ventral prostate of castrated animals receiving $1.2,2.4$ or $3.6 \mu \mathrm{g} / \mathrm{kg}$ per day DHT, SSG1 protein expression was similar to that of sham-operated rats. Although SSG1 protein expression in castrated rats receiving $1 \cdot 2$ or $2 \cdot 4 \mu \mathrm{g} / \mathrm{kg}$ per day testosterone was significantly higher $(P>0 \cdot 01)$ than SSG1 protein expression in castrated rats, testosterone was not as effective as DHT in restoring SSG1 protein levels to that expressed in control tissue. These results indicate that SSG1 protein expression is regulated by androgens and that SSG1 mRNA and protein expression, in response to androgen withdrawal and replacement in the ventral prostate, are discordantly regulated. 
A

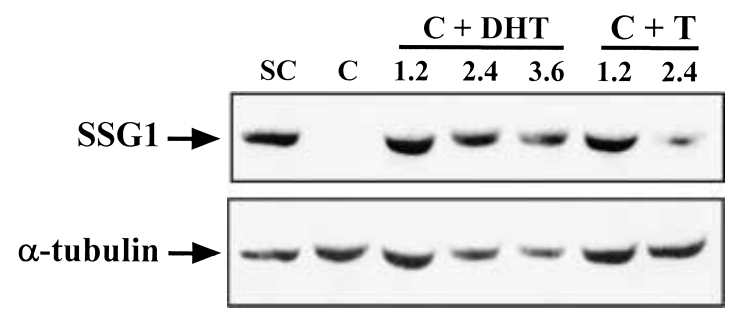

B

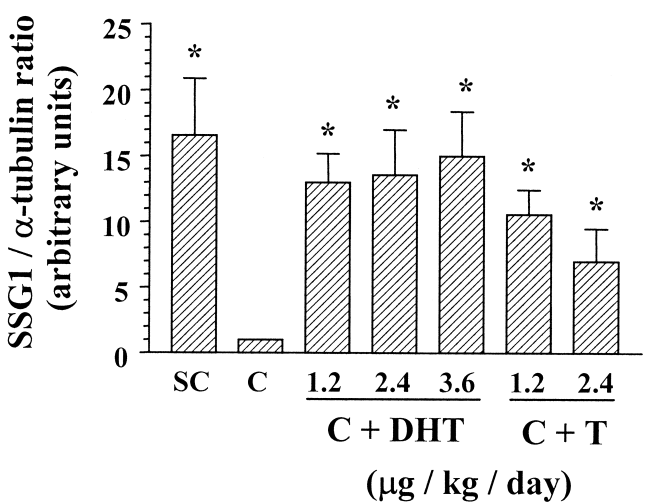

FIGURE 3. Effect of castration and androgen replacement on SSG1 protein expression in the ventral prostate. (A) $75 \mu \mathrm{g}$ total protein extracted from the ventral prostate of sham-castrated (SC, $n=3)$,

2-week-castrated (C, $n=3$ ) or 2-week-castrated rats treated with $1 \cdot 2,2 \cdot 4$ or $3 \cdot 6 \mu \mathrm{g} / \mathrm{kg}$ per day DHT or $1 \cdot 2$ or $2 \cdot 4 \mu \mathrm{g} / \mathrm{kg}$ per day testosterone ( $\mathrm{T}, n=3$ ), for 21 days, were separated on a $10 \%$ SDS-PAGE gel. Blots were probed with anti-SSG1 or anti- $\alpha$-tubulin antibodies as indicated. A representative blot is shown. (B) SSG1 and $\alpha$-tubulin expression were quantitated by densitometric scanning of the autoradiograms. SSG1 expression was normalized to $\alpha$-tubulin expression and is plotted. Values are expressed in arbitrary units with the means \pm s.E. shown. Statistical significance $(P<0 \cdot 01)$, when compared with protein expression in the ventral prostate of castrated rats, is indicated by an asterisk.

\section{Finasteride does not regulate SSG1 mRNA or protein levels in the rat ventral prostate in vivo}

In androgen-dependent target cells, $5 \alpha$-reductase converts testosterone to the more potent androgen DHT (Gormley 1992). Finasteride, a steroid analogue, competitively inhibits $5 \alpha$-reductase activity resulting in an increase in intraprostatic testosterone levels by about 10 -fold and the suppression of serum and intra-prostatic DHT concentrations to castration-equivalent levels (Gormley 1992). SSG1 mRNA and protein expression were measured in the ventral prostates of intact

www.endocrinology.org rats treated with $10 \mathrm{mg} / \mathrm{kg}$ finasteride daily for 21 days. As indicated in Fig. 4A and B, SSG1 mRNA expression does not significantly differ in the prostates of control-treated rats versus SSG1 mRNA expression in the prostates of finasteridetreated rats. Furthermore, SSG1 protein expression in control-treated prostates did not significantly differ when compared with SSG1 expression in finasteride-treated samples (Fig. 4C and D) although treatment with this antiandrogen resulted in a significant $(P<0.05)$ decrease in ventral prostate weight (data not shown).

\section{Immunofluorescent localization of SSG1 in the rat ventral prostate}

The site of SSG1 protein expression in the normal rat ventral prostate was investigated by immunofluorescent analysis using a SSG1-specific antibody (Fig. 5). A strong immunofluorescent signal was predominantly located to the prostatic smooth muscle cells (panels A and B, arrowhead) and to the vascular smooth muscle cells (panel $\mathrm{B}$, arrow) of the rat ventral prostate. Immunofluorescent labeling was also observed at lower levels in the epithelial compartment of the ventral prostate (panels $\mathrm{A}$ and $\mathrm{B}$, star). In panel $\mathrm{C}$, immunofluorescent labeling was performed in the absence of primary antiSSG1 antibody to demonstrate the non-specific component of the immunofluorescent signal.

\section{Treatment with androgens and antiandrogens in vitro does not regulate SSG1 protein expression}

LnCap prostate cancer cells of epithelial origin do not express detectable levels of SSG1 mRNA by Northern blot analysis and SSG1 mRNA remained undetectable following DHT treatment (data not shown). Nonetheless, Western blot analysis indicates that LnCap cells express SSG1 protein. Therefore, LnCap cells were treated with DHT (0, $1,5$ or $50 \mathrm{nM})$, cyproterone acetate, a steroidal anti-androgen, $(0,10,50$ or $500 \mathrm{nM})$ or flutamide, a non-steroidal antiandrogen, $(0,10$ or $500 \mathrm{nM})$ for $72 \mathrm{~h}$. As shown in Fig. 6A and B, SSG1 protein levels remain unchanged following androgen or antiandrogen treatment in vitro.

\section{DISCUSSION}

We previously demonstrated that SSG1 is regulated by $\mathrm{E}_{2}$ in the rat mammary gland in vivo. SSG1 protein expression is induced in the rat mammary 


\section{mg Finasteride}

A

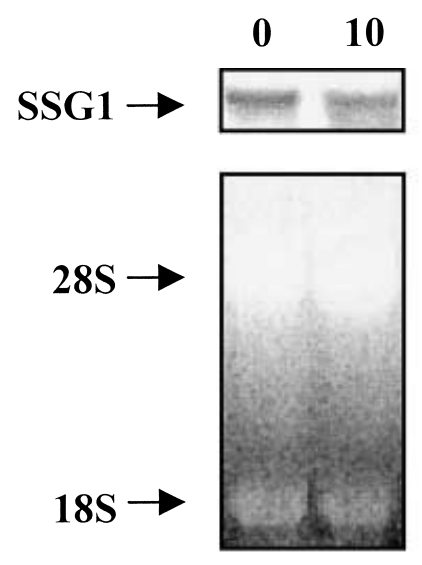

C

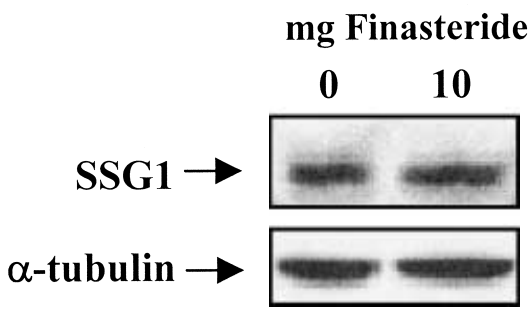

B

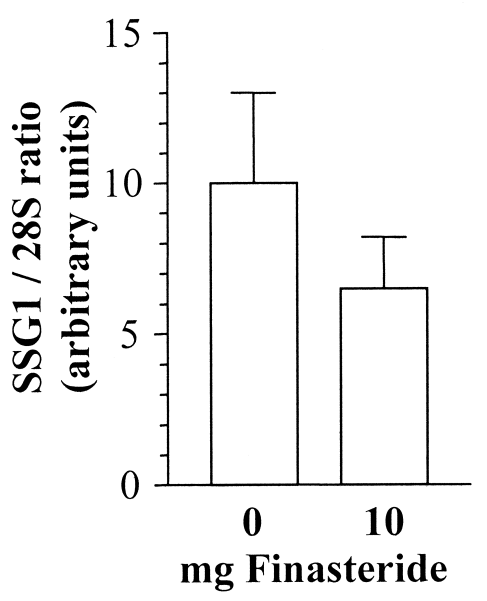

D

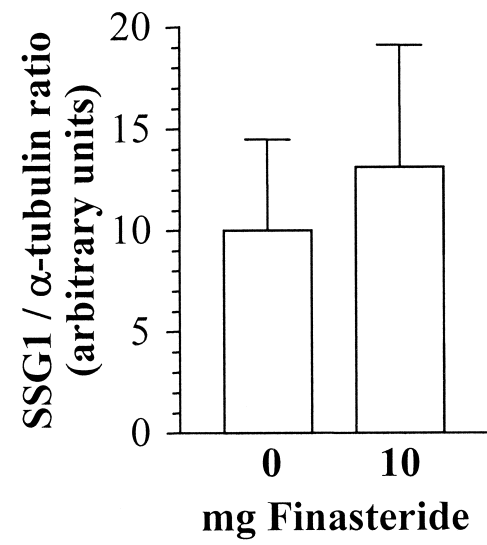

FIGURE 4. SSG1 mRNA and protein levels following finasteride treatment in the rat ventral prostate. Rats $(n=3)$ were treated with 0 or $10 \mathrm{mg}$ finasteride $/ \mathrm{kg}$ body weight daily for 21 days as indicated. A representative Northern blot analysis of SSG1 expression is shown in panel A. In panel B, levels of SSG1 mRNA expression were quantitated by densitometric scanning of autoradiograms and normalized to $28 \mathrm{~S}$ mRNA levels. Values are expressed in arbitrary units with the means \pm s.E. shown. A representative Western blot analysis of SSG1 protein expression in the ventral prostates of control and finasteridetreated rats is shown in C. SSG1 protein levels were quantitated by densitometry and normalized to $\alpha$-tubulin protein expression (D). Results are expressed in arbitrary units with the means \pm s.E. shown.

gland following a two-week exposure to superphysiological levels of $\mathrm{E}_{2}$ and is decreased following the removal of the $\mathrm{E}_{2}$ stimulus. Furthermore, SSG1 is overexpressed in the hormone-dependent DMBA-induced rat mammary tumors, suggesting that SSG1 may play a role in estrogen functions related to mammary carcinogenesis or may be a marker for breast cancer (Marcantonio et al. 2001). The objective of this study was to determine whether SSG1 would be regulated by steroid hormones in the prostate. Therefore the influence of androgens on the regulation of SSG1 in the ventral prostate was studied by investigating the mRNA expression pattern of SSG1 following castration.

In our studies, castration-induced androgen ablation increased SSG1 mRNA levels in a time-dependent manner when compared with SSG1 mRNA levels in sham-operated animals. Treatment of rats with regressed prostates with DHT or testosterone decreased SSG1 mRNA expression and was similar to levels of SSG1 expression in sham-castrated controls. These in vivo studies demonstrate that SSG1 mRNA expression is regulated, at least in part, by DHT and 

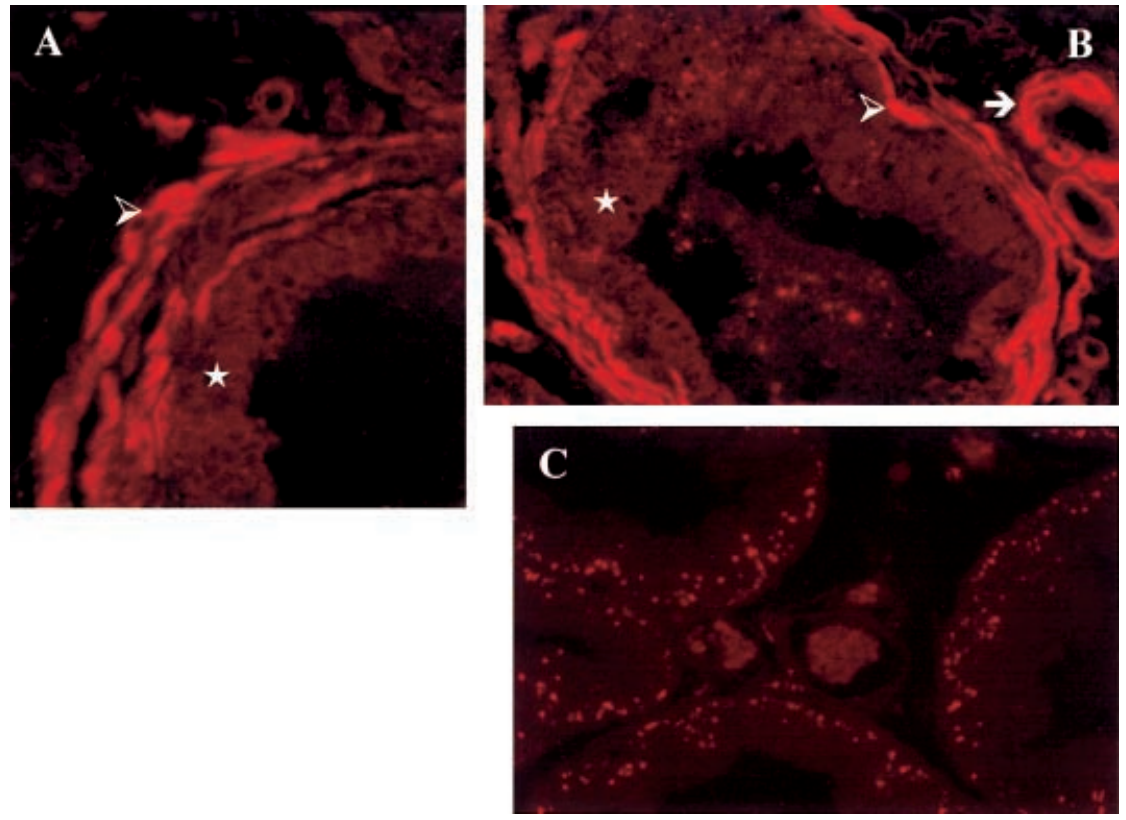

FIGURE 5. Immunofluorescent localization of SSG1 protein in the rat ventral prostate. Formalin-fixed, paraffin-embedded rat ventral prostate tissue sections were used in these studies. In panels A and B, the SSG1 protein was immunofluorescently labeled using an anti-SSG1 specific antibody and goat anti-rabbit IgG conjugated to Texas Red. Arrowheads indicate the SSG1 protein localized to the prostatic smooth muscle cells whereas SSG1 located to vascular smooth muscle is indicated by an arrow. SSG1 located to the epithelial cells of the prostate is indicated by a star. The negative experimental control in which primary antibody was omitted is shown in panel C.

testosterone in the rat ventral prostate and suggests that androgens may act to negatively regulate SSG1 mRNA expression. This is the first demonstration that SSG1 is regulated by androgens in a male reproductive tissue. In contrast to the SSG1 mRNA results, SSG1 protein levels dramatically decreased after castration. Androgen supplementation returned SSG1 to control levels of protein expression in the castrated rat. Thus, in the prostate, SSG1 mRNA and protein expression are discordantly regulated in response to androgens. We previously showed that SSG1 mRNA and protein expression were also discordantly regulated in the rat mammary gland following estrogen treatment (Marcantonio et al. 2001). Furthermore, a discordant pattern of AR mRNA and protein regulation in response to androgens was observed in LnCap prostate cancer cells and the AR-positive MDA453 breast cancer cells (Yeap et al. 1999). In LnCap and MDA453 cells, DHT treatment decreased total AR mRNA, but increased AR protein expression (Yeap et al. 1999). In LnCap cells, DHT down-regulated AR mRNA transcription but stabilized AR mRNA. In contrast, DHT destabilized AR mRNA yet had

www.endocrinology.org no effect on AR mRNA transcription in MDA453 cells (Yeap et al. 1999). This suggests an important role for post-transcriptional pathways in the regulation of gene expression by androgens which ultimately affect mRNA and/or protein expression. Although the mechanism of SSG1 regulation by androgens in the ventral prostate has not been determined, we propose that SSG1 undergoes tissue-specific translational and/or post-translational modifications that may ultimately affect SSG1 expression in the prostate.

Androgens play an important role in the male reproductive system; however, estrogens are also produced in the male (Griffin 1992). Seventy-five to ninety percent of male estrogen is formed by the peripheral aromatization of testosterone to $E_{2}$ and androstenedione to estrone in the adipose tissue. The remaining $10-25 \%$ of $\mathrm{E}_{2}$ and estrone is produced by the testes (Farnsworth 1999). In the rat ventral prostate, estrogen-receptor alpha is localized to stromal cells, both fibroblasts and smooth muscle cells, which are the primary target of estrogens, whereas estrogen-receptor beta is expressed in the luminal epithelial cells (Prins \& Birch 
A

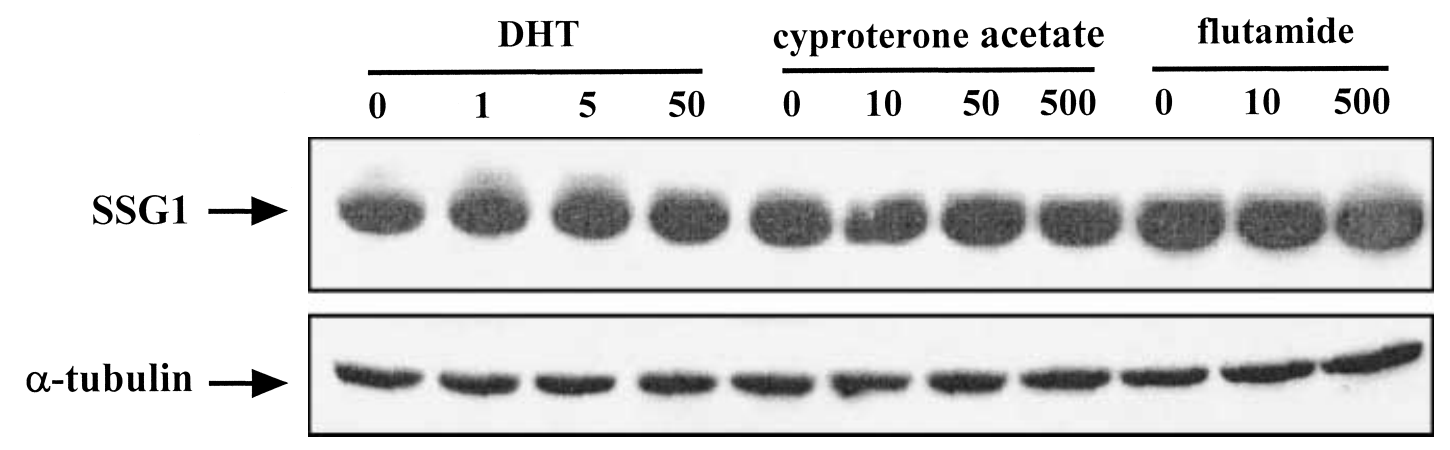

B
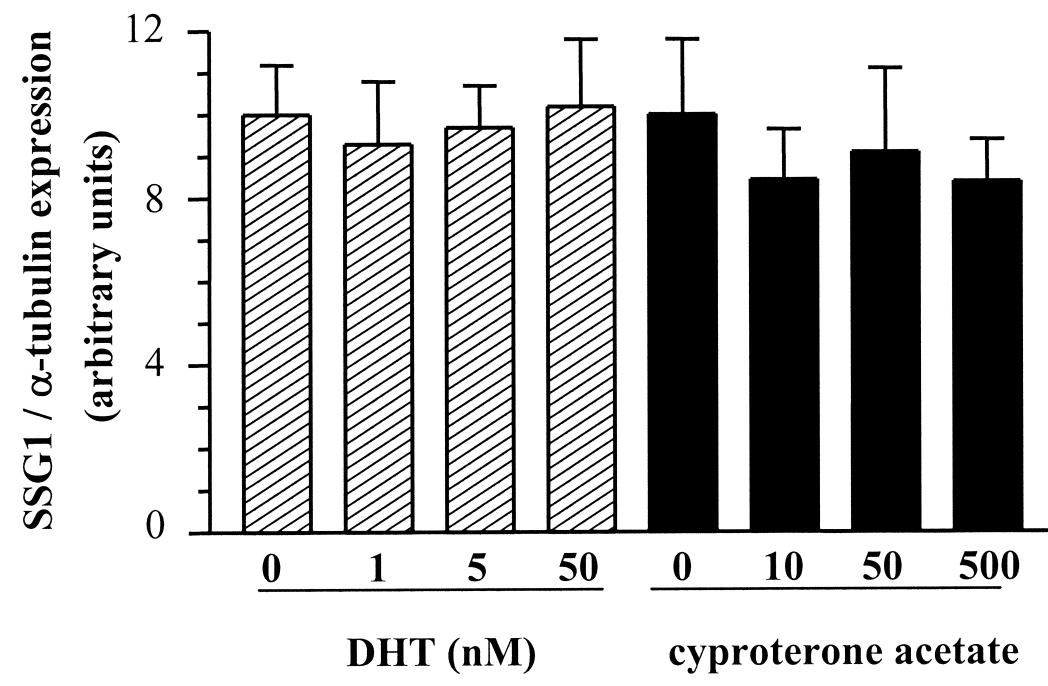

(nM)

Tutamide

$(\mathbf{n M})$

FIGURE 6. SSG1 protein levels are unchanged in LnCap cells following treatment with DHT or antiandrogens. (A) Western blotting was performed on $75 \mu \mathrm{g}$ total protein extracted from LnCap cells treated with nanomolar concentrations of DHT, cyproterone acetate or flutamide for $72 \mathrm{~h}$ using an anti-SSG1 or an anti- $\alpha$-tubulin antibody as indicated $(n=3)$. A representative Western blot is shown. (B) SSG1 and $\alpha$-tubulin protein expression were quantitated by densitometric scanning of the autoradiograms. SSG1 expression was normalized to that of $\alpha$-tubulin and results are plotted. Values are expressed in arbitrary units with the means \pm s.E. shown.

1997, Chang et al. 1999, Chang \& Prins 1999). In our study finasteride treatment of rats did not significantly alter SSG1 mRNA or protein expression in the rat ventral prostate in vivo. Finasteride is an anti-androgen which inhibits the activity of $5 \alpha$-reductase required for the conversion of testosterone to the more potent androgen DHT (Gormley 1992). Although finasteride reduces the levels of intraprostatic DHT, treatment with this antiandrogen is not equivalent to castration-induced androgen ablation. Finasteride treatment results in a 10 -fold increase in intraprostatic testosterone concentration in rats and in humans, which can be metabolized to estrogens (Geller 1990, McConnell et al. 1992). Therefore the lack of significant regulation of SSG1 expression in response to finasteride in the ventral prostate of intact rats suggests that SSG1 is regulated by testosterone but also potentially by estrogens. With increasing age, the ratio of androgens to estrogens is decreased due to the rise in estrogen production and is accompanied by the development of benign prostatic hyperplasia, a stromal disease associated with increased serum $\mathrm{E}_{2}$ level (Levine et al. 1997). Therefore, the role of estrogens in SSG1 modulation in the rat ventral prostate warrants further investigation in view of the potential role of estrogens in prostate disease.

The SSG1 protein was highly expressed in the prostatic smooth muscle cells and the smooth muscle component of the vasculature in vivo. Prostatic smooth muscle cells are AR-positive, and 
are the primary target of androgen action in the adult prostate stroma (Gerdes et al. 1996). The adult prostate requires androgens to maintain smooth muscle cell differentiation and is probably dependent on expression of the AR in prostatic smooth muscle (Hayward et al. 1997). It has been proposed that the differentiated prostatic smooth muscle of the adult prostate stroma is a key player in the microenvironment of the prostate epithelium (Cunha et al. 1996). Thus, prostatic smooth muscle cells maintain epithelial structure and function and conversely, prostatic epithelium maintains smooth muscle differentiation (Cunha et al. 1996). Furthermore, the interaction between stroma and epithelium via stimulatory and inhibitory peptides, such as epidermal growth factor (EGF), transforming growth factor (TGF)- $\alpha$, TGF- $\beta$, insulinlike growth factors (IGFs) and fibroblast growth factors (FGFs) maintains normal prostate growth (Hiramatsu et al. 1988, Hofer et al. 1991, Kyprianou \& Isaacs 1989, Peehl et al. 1995, Story 1995). Damage to the prostatic epithelium may result in aberrant epithelial to smooth muscle signaling. Consequently, smooth muscle cells de-differentiate resulting in abnormal smooth muscle to epithelial signaling (Hayward et al. 1997). Due to the lack of androgen-responsive prostate stromal cell lines, advances in the identification of key androgen-regulated prostate stromal genes has been limited. This is despite the fact that characterization of androgen-regulated gene expression in prostate smooth muscle is critical to the study of the mechanisms involved in developmental differentiation and growth control of the prostate, as well as in the progression of benign and neoplastic prostatic disease (Gerdes et al. 1996). Thus, our finding that SSG1 is an androgen-responsive gene in vivo and is expressed in prostatic smooth muscle is of importance. SSG1 was not regulated by DHT in the androgen-responsive LnCap prostate cancer cells which are of epithelial origin and, thus, androgen responsiveness may be limited to prostatic smooth muscle cells. Although the role of androgens is important, alone they are insufficient to maintain normal prostate homeostasis. In adulthood, normal prostatic growth and differentiation are mediated by the local synthesis and action of paracrine signaling molecules (Lee 1997). Prostatic homeostasis requires complex interactions between EGF, TGF- $\alpha$, TGF- $\beta$, IGFs and FGFs with their receptors, which may be regulated by androgens or independently by other factors (Hiramatsu et al. 1988, Hofer et al. 1991, Kyprianou \& Isaacs 1989, Peehl et al. 1995, Story 1995). Therefore peptide growth factors may also contribute to SSG1 regulation following castration and androgen

www.endocrinology.org replacement in the rat ventral prostate. At this time, the function of SSG1 is unknown. In the prostate, androgens regulate three major cellular processes: proliferation, differentiation and apoptosis. Therefore, SSG1 may well be involved in the regulation of these cellular events in response to hormonal manipulation in vivo.

\section{REFERENCES}

Chang WY \& Prins GS 1999 Estrogen receptor-beta: implications for the prostate gland. Prostate 40 115-124.

Chang WY, Wilson MJ, Birch L \& Prins GS 1999 Neonatal estrogen stimulates proliferation of periductal fibroblasts and alters the extracellular matrix composition in the rat prostate. Endocrinology 140 405-415.

Colombel MC \& Buttyan R 1995 Hormonal control of apoptosis: the rat prostate gland as a model system. Methods in Cell Biology 46 369-385.

Cunha GR, Donjacour AA, Cooke PS, Mee S, Bigsby RM, Higgins SJ \& Sugimura Y 1987 The endocrinology and developmental biology of the prostate. Endocrine Reviews $\mathbf{8}$ 338-362.

Cunha GR, Hayward SW, Dahiya R \& Foster BA 1996 Smooth muscle-epithelial interactions in normal and neoplastic prostatic development. Acta Anatomica 155 63-72.

Farnsworth WE 1999 Estrogen in the etiopathogenesis of BPH. Prostate 41 263-274.

Flickinger CJ 1972 The fine structure of the interstitial tissue of the rat prostate. American Fournal of Anatomy 134 107-125.

Geller J 1990 Effect of finasteride, a 5 alpha-reductase inhibitor on prostate tissue androgens and prostate-specific antigen. Fournal of Clinical Endocrinology and Metabolism $\mathbf{7 1}$ 1552-1555.

Gerdes MJ, Dang TD, Lu B, Larsen M, McBride L \& Rowley DR 1996 Androgen-regulated proliferation and gene transcription in a prostate smooth muscle cell line (PS-1). Endocrinology 137 864-872.

Gormley GJ 1992 Chemoprevention strategies for prostate cancer: the role of 5 alpha-reductase inhibitors. Fournal of Cell Biochemistry 16H 113-117.

Griffin JE 1992 Male reproductive function. In Textbook of Endocrine Physiology, edn 2, pp 169-188. Eds JE Griffin \& SR Ojeda. New York: Oxford University Press.

Hayward SW, Baskin LS, Haughney PC, Foster BA, Cunha AR, Dahiya R, Prins GS \& Cunha GR 1996 Stromal development in the ventral prostate, anterior prostate and seminal vesicle of the rat. Acta Anatomica 155 94-103.

Hayward SW, Rosen MA \& Cunha GR 1997 Stromal-epithelial interactions in the normal and neoplastic prostate. British Fournal of Urology 79 18-26.

Hiramatsu M, Kashimata M, Minami N, Sato A, Murayama M \& Minami N 1988 Androgenic regulation of epidermal growth factor in the mouse ventral prostate. Biochemistry International 17 311-317.

Hofer DR, Sherwood ER, Bromberg WD, Mendelsohn J, Lee C \& Kozlowski JM 1991 Autonomous growth of androgen-independent human prostatic carcinoma cells: role of transforming growth factor alpha. Cancer Research $\mathbf{5 1}$ 2780-2785.

Huynh H 1998 In vivo regulation of the insulin-like growth factor system of mitogens by human chorionic gonadotropin. International Fournal of Oncology 13 571-575. 
Kyprianou N \& Isaacs JT 1988 Activation of programmed cell death in the rat ventral prostate after castration.

Endocrinology 122 552-562.

Kyprianou N \& Isaacs JT 1989 Expression of transforming growth factor-beta in the rat ventral prostate during castration-induced programmed cell death. Molecular Endocrinology 3 1515-1522.

Lee C 1997 Cellular interactions in prostate cancer. British Fournal of Urology 79 21-27.

Levine AC, Kirschenbaum A \& Gabrilove JL 1997 The role of sex steroids in the pathogenesis and maintenance of benign prostatic hyperplasia. Mount Sinai fournal of Medicine 64 $20-25$.

Lopez-Otin C \& Diamandis EP 1998 Breast and prostate cancer: an analysis of common epidemiological, genetic, and biochemical features. Endocrine Reviews 19 365-396.

McConnell JD, Wilson JD, George FW, Geller J, Pappas F \& Stoner E 1992 Finasteride, an inhibitor of 5 alpha-reductase, suppresses prostatic dihydrotestosterone in men with benign prostatic hyperplasia. Fournal of Clinical Endocrinology and Metabolism 74 505-508.

Marcantonio D, Chalifour LE, Alaoui-Jamali MA, Alpert L \& Huynh HT 2001 Cloning and characterization of a novel gene that is regulated by estrogen and is associated with mammary gland carcinogenesis. Endocrinology 142 (In Press).

Peehl DM, Cohen P \& Rosenfeld RG 1995 The insulin-like growth factor system in the prostate. World Fournal of Urology 13 306-311.

Prins GS \& Birch L 1997 Neonatal estrogen exposure up-regulates estrogen receptor expression in the developing and adult rat prostate lobes. Endocrinology 138 1801-1809.

Shabisgh A, Tanji N, D'Agati V, Burchardt M, Rubin M, Goluboff ET, Heitjan D, Kiss A \& Buttyan R 1999 Early effects of castration on the vascular system of the rat ventral prostate gland. Endocrinology 140 1920-1926.

Story MT 1995 Regulation of prostate growth by fibroblast growth factors. World Fournal of Urology 13 297-305.

Wilding G 1995 Endocrine control of prostate cancer. Cancer Surveys 23 43-62.

Yeap BB, Krueger RG \& Leedman PJ 1999 Differential posttranscriptional regulation of androgen receptor gene expression by androgen in prostate and breast cancer cells. Endocrinology 140 3282-3291.

RECEIVED 23 October 2000

ACCEPTED 9 February 2001 